\title{
Revisiting Iran through Women's Memoirs: Alternative Narratives from Insider Within
}

\author{
Esmaeil Zeiny ${ }^{a}$ \\ e.zeiny@gu.ac.ir \\ Department of English Language and Literature, \\ Golestan University, Iran \\ Noraini Md Yusof \\ animy@ukm.edu.my \\ Institute of Malaysian and International Studies, \\ Universiti Kebangsaan Malaysia, Malaysia \\ Abdolbaghi Rezaei Talarposhti \\ a.rezaei@gu.ac.ir \\ Department of English Language and Literature, \\ Golestan University, Iran
}

\begin{abstract}
Life narratives of the Iranian women in the diaspora, which have become very popular in recent years, have long served as a model for understanding Iran for western readers. This popularity is emanated from the curiosity and interest in the west that was raised after $9 / 11$ and the ensuing political aftermath. Written to unveil the lives of Iranian women in the Islamic Republic, these diasporic narratives have been 'growingly commodified, circulated and consumed uncritically' in the west. Much ink has been spilled on the surge of diasporic Iranian women's life narratives, the politics of their reception and circulation in the west, and their liability to furthering imperialist ideologies. We have no intention of continuing the debate over how some of these life narratives facilitate and promote imperialistic agendas. Rather, we would like to embark on an untrodden path, a fascinating journey through the growing body of life narratives by and about Iranian women from inside the Islamic Republic, equipped with accounts that vitiate the orientalist assumptions and diasporic narratives' generalisations. This paper seeks to introduce and analyse these alternative narratives. By developing a theory of the 'insider within,' this paper exhibits how alternative narratives from within can serve as a better model for understanding Iran and Iranian women.
\end{abstract}

Keywords: Iranian women; alternative narrative, diasporic narrative; insider-outsider positionality; self-definition \& self-valuation

\section{INTRODUCTION}

Memoirs of the Iranian women in the diaspora, which have grown exponentially in recent years, have long been the model for western readers interested in Iran and Iranians. A search on Amazon (Iran, women, memoir) also mostly yields to memoirs of diasporic Iranian women writers. This unprecedented burgeoning of memoirs is derived from a particular interest and inquisitiveness in the west that was piqued after $9 / 11$ and the subsequent political aftermath. Penned to unveil the lives of Iranian women and disclose the dissimulations that mask Iranian women's tendencies, feelings and thoughts, these narratives have been growingly commodified, circulated and consumed uncritically in the west. These diasporic narratives are taken for granted and are usually rendered as "authentic and authoritative" stemming from their

${ }^{a}$ Main \& corresponding author 
authors' assumed insider-outsider positionality. Many of these narratives reiterate the orientalist stereotypes, reinforce the western assumptions, and reproduce the reductive but familiar accounts of the plights of veiled, voiceless and submissive Iranian women living in the Islamic Republic. It is necessary to note at the outset of this paper that we have no intention of wresting the agency from these diasporic writers and reducing them all to writers that foster the orientalist generalisations and assumptions about Iran, and Iranian women. We rather feel that it is certainly rewarding that these women are voicing their concerns against some discriminatory policies through narratives and are willing to take agency for their life stories. However, we feel alienated to see exaggerated, one-sided and out-of-context accounts in many of these narratives.

All the generalisations and out-of-context accounts make these diasporic narratives appear to regenerate the neo-liberal advocacy of imperialism when they simultaneously seem to circulate disinterestedly. We are not arguing that all these narratives are deliberately furthering the imperialist agenda but the sociopolitical contexts into which they are received can steer the interpretation that way. The peril with these narratives arises when they become the standard for understanding Iran and Iranian women. For instance, Azar Nafisi's Reading Lolita in Tehran (2003) which topped the New York Times bestseller list for more than ninety weeks has been a popular memoir to understand Iran and Iranian women. The book has also made it to universities' curriculum across North America in disciplines of Middle Eastern Studies, International Relations, and Women's Studies. Marjane Satrapi's graphic memoir, Persepolis (2003) which has been another source of understanding Iran and Iranian women was one of the reading items in West Point, the United States Military Academy in 2006. This peril of becoming a model to understand Iran along with the politics of reception and circulation of these narratives has already been delved into by many critics who are quick to point fingers at the problematic depictions of Iran and Iranian women. We argue that calling attention to these questionable portrayals is not enough to eliminate the peril. Instead, it is best to bring what we term, 'alternative narratives from insider within' to western readers' attention interested in Iran. These alternative narratives are counter-narratives that delegitimise the generalised and one-sided perspectives of diasporic narratives. This paper seeks to introduce and analyse these alternative narratives. By developing a theory of the 'insider within,' this paper exhibits how narratives from within are a better model for understanding Iran and Iranian women; this paper also reveals how the assumed insider-outsider positionality of the diasporic authors would not necessarily produce an authentic and authoritative narrative.

\section{DELEGITIMISING THE DIASPORIC INSIDER-OUTSIDER POSITIONALITY}

For over four decades since the 1979 Islamic Revolution and more than a decade after 9/11, Iranian women writers in the diaspora have been creating life narratives that have been regarded as 'authentic and authoritative' by many readers in the west. This authenticity hails from both the genre's hereditary claim to fidelity and the insider/outsider positionality of the diasporic writers. Many readers consider this positionality as a combination of accuracy and objectivity. The insider status which derives from their nativity allows a faster and more thorough acceptance by the readers; and the outsider status which stems from their orientalist perspective of Iran and the veiled Muslim women associates them with whiteness. Diasporic Iranian women writers' engagement with western cultures, practices and values in their narratives is also an effort to accentuate the whiteness and strengthen their outsider status. This whiteness is an invisible privilege that connects these diasporic authors to their western readers. To achieve a stronger connection with the western readers in order to reinforce their outsiderness, the diasporic authors establish marginality in the Other's civilisation. One way to produce marginality in the diasporic life narratives is the depiction of the experiences of 
estrangement. For many diasporic authors of life narratives, Whitlock argues (2007, p. 165), life in post-revolutionary Iran is presented as "an experience of estrangement, a little death of the self and a painful loss of the known world." The most important locator of estrangement for diasporic authors is Iran's transmutation into a state of Islamic Republic after the 1979 Revolution and enforcing Islamic rules and regulations such as veiling. The account on veiling, for instance, starts right from the covers of these memoirs to reinforce the notion of exotic East and Iranian women's submissiveness in the patriarchal society (Zeiny and Noraini Md. Yusof, 2016). This performed marginality, indeed, evokes sympathy in western readers and make their narratives more reliable. With this, they use the 'soft weapon' of their life narratives to envision themselves out of the Islamic Republic of Iran. Whitlock (2007, p. 3) argues that a life narrative can be a "soft weapon" not only because of its ability in lending voices to unheard and unseen stories, but also since life narratives are:

easily co-opted into propaganda. In modern democratic societies propaganda is frequently not the violent and coercive imposition of ideas but a careful manipulation of opinion and emotion in the public sphere and a management of information in the engineering of consent. Life narrative can be complicit in these processes.

For this outsider, the criteria of authenticity and objectivity prove impertinent as $\mathrm{s} / \mathrm{he}$ is constantly engaged in a symbiotic act of sameness with westerners and marginalisation in the Other's civilisation. This outsider's symbiotic act of 'I am like you' and 'I am different' is an effort to convince the western audience of the veracity of a diasporic narrative. Of important criterion in this outsider's narrative is drawing attention to the differences to sustain the SelfOther relationship. It is this outsiderness that brings about an ideal insider for western imperialism. This conjures up Trinh T Minh Ha's ideal insider who "is the psychologically conflict-detecting and problem-solving subject who faithfully represents the Other for the Master...more specifically, the Master's self-other relationship in its enactment of power relations, gathering serviceable data, minding his/her own business-territory, and yet offering the differences expected" (1991, p. 68). Trinh T Minh Ha continues "what can be more authentically "other" than an otherness by the Other him/herself?" (p. 69). Anchored within such discourse, the positionality and the claim to authenticity and legitimacy are subject to cross-examination. The assumed insider/outsider positionality confers the diasporic authors a leeway in reiterating orientalist clichés and writing in generality. What has gone unnoticed for many critics and readers is the fact that the diasporic Iranian women authors' insider status does not have a solid validity as well. This begets the question of 'what is it that an insider is insider of?' Although the narrators recount their own life stories, the insiders represent fellow men and women, culture and tradition of their community too. An insider is someone who lives inside a community, belongs fully to the community and flourishes in it, and has direct and first-hand knowledge about the sociopolitical phenomenon of the past and present in the community. Now since a life narrative is all about recalling a specific period of time in the past, this raises the question of 'what does the past have to do with the present?' It is important to note that the past does not stand independently as some "fixed storage of historical residue, from which collectivities or individuals may draw consistent and unchanging deposits" (Trouillot, 1995, pp. 14-15). Remembering is also not a passive process and continually evokes a reinterpretation of the past in the present. The memory of an event took place in the past reflects an amalgamation of information encoded at the time it occurred and it is influenced by the authors' presence within particular social settings of the present. Authors seem to be writing on the past and fully saturated in it but in actuality it is the present that overshadows and informs the writing of the past (Mandel, 1980, pp. 64-65). Therefore, memories are not devoid of the sociopolitical and cultural contexts of the present. 
Simply put, being present now and then bestows one an insider status. Many of the diasporic authors were born and raised in Iran but they had left the country a long time ago and moved to the west. The "moment the insider steps out from the inside, she is no longer a mere insider (and vice versa). She necessarily looks in from the outside while also looking out from the inside" (Trinh T Minh Ha, 1991, p. 74). Their present absence in the homeland and their current presence in the hostland rub them off the insider status. That said, the diasporic authors' remembering of the past events is oftentimes affected by the sociopolitical settings of the hostland. The present seems to be inseparable from the past. This explains why many readers take the delayed accounts of the past as details of the present. For instance, despite the diasporic Iranian women authors' normally self-proclaimed historically dated setting, these narratives are mostly taken to be current accounts of Iranian society and sociopolitical phenomenon in the country. One prime example is Azar Nafisi's Reading Lolita in Tehran (2003) that chronicles life in Iran between 1979 and 1997. Although Nafisi admits in her epilogue that Iranian women's situation has drastically changed for the better and they have gained many rights since the time of her own experiences, her self-admitted time delay of circumstances has gone overlooked so much so that the episodes in her life narrative are taken as the current episodes of women's oppression and their lack of freedom under the Islamic Republic. According to Whitlock (2007), these narratives "appear at one and the same time as unfamiliar and belated to contemporary Iranians, and familiar and welcome to contemporary American readers" (p. 165). The unfamiliarity to contemporary Iranians is suggestive of a weakness in the insider status. Thus far, we have shown how diasporic authors' assumed insider-outsider positionality or the ostensible combination of accuracy and objectivity is invalid and far away from the true insider-outsider positionality. Therefore, their interventions and accounts are necessarily those of both not quite an insider and not quite an outsider. Although birth, residency for a period of time, and cultural heritage would give diasporic writers a 'partial insider' status, these authors cannot adopt an 'insider within' status by virtue of birth and residency for a period of time. We, instead, catagorise this partial insiderness as the 'insider without' as the diasporic writers moved out of the inside. Having delegitimised the diasporic Iranian insider-outsider's positionality in producing life narratives, it is now time to theorise and introduce alternative narratives from the 'insider within' that can serve as better models for understanding Iran and Iranian women.

\section{THE INSIDER WITHIN}

The 'insider within' shares similarities with Christina Chavez's “total insider" (1980). We argue that of vital importance in having the "total insider" or what we term the 'insider within' status is sharing the multiple identities (e.g., race, ethnicity, class, religion) with the community. Most of the Iranian women authors in the diaspora are western educated or western-style educated and are amongst the privileged sect of the society; and therefore, they are not sharing various identities with the community they are writing about. Banks 1998 characterisations of an 'indigenous-insider' researcher tally perfectly with what we have in mind about the 'insider within.' Having been socialized in the community, the insider within can write of "unique values, perspectives, behaviors, beliefs, and knowledge of his or her indigenous community and culture and is perceived by people within the community as a legitimate community member who can speak with authority about it" (p. 8). The "insider within' can speak of and speak for the community since they understand the cognitive, emotional, and psychological percepts of the community and has a more thorough and profound knowledge of the historical events due to their presence. We contend that Iranian women writers of life narratives from inside Iran fit well into the catagorisation of the 'insider within' status. They owe this status to their full presence in the country, first-hand and direct 
knowledge about the sociopolitical phenomenon of the past and present of Iran, and sharing of several identities with whom they are writing about. The Iranian women writers of life narratives from inside Iran have the potential to use perspectives from their experiences in order to bring a new lens that reflects Iranian women and society. We argue that the 'insider within' in this context has two substantial traits: 1) Iranian women's self-definition and selfvaluation; 2) the significance of Iranian women's culture. Self-definition is interrogating the political knowledge-validation process that has eventuated in extraneously-defined, stereotypical images of Iranian womanhood; and self-valuation emphasises the content of Iranian women's self-definitions and involves the replacement of extraneously-derived images with authentic Iranian female images. The extraneously-derived images are the stereotypes in the diasporic narratives that have been central to the demonisation and dehumanisation of Iran and Iranian society. Therefore, self-definition and self-valuation question these stereotypes and repudiate the credibility and the motives of those possessing the power to define. When Iranian women in the country define themselves through their life narratives, they would unveil the formerly unexplored areas of their experiences; consequently, this highlights the importance of Iranian women's culture.

This genre of literature produced by Iranian women from inside the country deal with women's issues and gender relations. However, unlike the diasporic life narratives that offer a static image of women victimhood, immobility, subordination and entrapment, life narratives written by Iranian women from inside the country represent Iranian women with voice and agency. This 'insider within' status provides a particular viewpoint on self, family, culture, tradition and society. These life narratives challenge the accounts of diasporic writers and make evident what was unseen in diasporic life narratives; these diasporic narratives have ostensibly been championing Iranian women's rights but in reality they promote stereotypes and denigrate Iranian women's achievements. Iranian women's life narratives produced by the 'insider within' are, indeed, counter-narratives that trouble the hegemonic diasporic narrative of 'the oppression of Iranian women' which positions the Iranian women in a subordinate level. These counter-narratives provide alternative narratives that have the potential to question orientalist stereotypes and make readers realise that the diasporic Iranian women's life narratives cannot serve as a standard to understand Iran and Iranian women. Many would argue that the 'insider within' is also susceptible to produce prejudiced narratives. While it is true that there is a degree of prejudice in any kind of narrative, a life narrative produced by the 'insider within' is critical of both local and global contexts. Seen in this light, the prejudice pales in comparison with the prejudice and partiality of the diasporic narratives which have become the dominant narratives in the west. To eliminate this predominance, bringing the narratives of the 'insider within' alternative narratives rooted in one's culture and tradition that deconstruct and delegitimise the one-sided views of diasporic narratives - from the periphery to the fore is crucial.

\section{ALTERNATIVE NARRATIVES}

The emergence of women's memoir in Iran can be traced back to Taj-ol-Saltanah's Memoir (1924) which was not published until 1982. Three decades after Taj-ol-Saltaneh penned her memoir, Maleke-ye E'tezadi and Masoumeh Azizi Borujerdi, a.k.a. Banu Mahvash published their unconventional life narratives. This era has also seen Shams Pahlavi's memoirs published in installments in Etela'at Mahiyaneh. With the advent of the Islamic Republic, it has often been argued that Iran is turning the clock back on women and would turn them into a nonexistence figure. Much to the chagrin of the critics who argue that women would have no public and literary presence in the Islamic Republic, "writing by Iranian women has increased exponentially since 1979" (Geoffrey Nash, 2012, 56). Critics such as Sanaz Fotouhi (2015) further contend that despite the conspicuous increase in writing by Iranian women in the world 
of literature, the tradition of forbidding women to bring their life to the surface lingered to this era. What has escaped these critics' attention is the growing number of life narratives produced by Iranian women from inside Iran. Many of these life narratives possess those two valuable traits of women's self-definition and self-valuation; and the significance of Iranian women's culture. These life narratives trouble those diasporic narratives' that perpetuate the currency of orientalist writing and representation. The writers of these life narratives push back against the reductive mainstream stories about Iran and Iranian women. Marivan Lake at Six O'clock (1981) is one such life narrative by Parvin Nowbakht that revolves around the 1979 Kurdish rebellion. Published by 'Islamic Thought and Art Organization' in Iran, the book is also a narration of simple and innocent love. Contrary to diasporic narratives' representations of life in the immediate years after the 1979 Revolution as a time when concepts such as 'love, personal and individual affection, and feminine feelings' would have been deliberately suppressed and ignored, this life narrative abounds with accounts on such concepts scattered throughout the book. For instance, Parvin writes: "It is strange that the first time I saw Sadegh, I realised that he was different from other boys, and I liked his behavior" (p. 47). Parvin has no fear to divulge that she, a university student, fell in love with a high school student who was a few years younger than herself. She writes: "Many appeared at Sadegh's grave including his classmates. I was convulsed with laughter to see that some high school kids gathered around Sadegh's grave. But of course, Sadegh was different from them" (p. 88). The very act of bringing her inner feelings to the surface and writing this personal narrative not only challenges the diasporic narratives but also questions the underlying patriarchy deeply rooted in the Iranian psyche.

Another prominent example but equally less noticed life narrative outside the borders of Iran is Masoumeh Ramhormozi's Eternal Fragrance (2003). It is an account of Iran-Iraq war, the fall and the subsequent conquest of Khorramshahr, told by a fourteen-year-old girl who worked as a social worker in the front. This narrative breaks the exclusive grips that men had in the literary production of the Iran-Iraq war or what has been referred to as 'Sacred Defense' in which women were almost always portrayed as faithful housewives and mothers of the martyrs. It brings to the fore the fact that although the eight years of Sacred Defense is replete with stories of men who stood up and defended their geographical and religious boundaries, it is also the saga of endurance and sacrifice of the Iranian women, secular and religious, Muslim and non-Muslim, in the battlefronts. It highlights the roles of Iranian women who participated in the Iran-Iraq war and it is suggestive of the fact that Iranian women do not have a lower position than men in defending the country. This life narrative, indeed, protests against the views that women are weak and submissive. For instance, Masoumeh questions the existing patriarchal assumption that "men are women's guardians in the battlefront" (p. 201). Her pride in holding a G3 rifle in the battlefront to defend the country (p. 46), her strength in observing the martyrs' body pieces (p. 51) and her ability not to cry when she sees her brother's corpse (p. 52) are all indicative of Iranian women's courage and tenacity. She writes: "defending the country has been a momentous issue and we could not turn a blind eye to it. Not in any possible way could we have stayed put and remained inactive due to our gender" (p. 65). In this vein, she challenges both the Iranian patrilineal cultural patterns and the Orientalist assumptions of Iranian women who are regarded as victims and stripped of agency. Unlike diasporic narratives in which only western literature is almost always regarded highly, alternative life narratives from the insider within speak of both Iranian and western literature. For instance, while Masoumeh read Forough Farokhzad, Samad Behrangi, Ali Shariati and Ayatollah Morteza Motahhari, she speaks of Jack London's The Call of the Wild (1903), Charles Dickens' Oliver Twist (1838), and Lottie and Lisa (1949) by Erich Kästner (pp. 2325). This, in and of itself, shows that this life narrative is far away from being one-sided. As one of the early works by and about Iranian women who have participated in the Iran-Iraq war, 
Eternal Fragrance was ranked the second book in the 9th Sacred Defense Book of the year awards. It has been enthusiastically received by the Iranian readers and paved the way for the publication of similar works. However, its English version translated by Farahnaz Omidvar and launched at the 66th Frankfurt Book Fair in 2014 has never received any sort of attention from media and reviewers.

Within the genre of 'Sacred Defense' literature, One Woman's War: Da (Mother) (2008/2014) is another memoir told by Seyyedeh Zahra Hosseini about her experiences during the Iran-Iraq war as recorded by Seyyedeh Azam Hosseini. This alternative narrative contains three parts: the first past details the narrator's childhood in Iraq and her migration to Iran; the second part which is the core part of this memoir is a depiction of the seventeen-year old Hosseini's volunteered activities such as nursing the wound, washing the corpses of the dead, and her role as a combatant in defending Khorramshahr; and the last part details the narrator's recovery from shrapnel injury she received from the battlefield and her married life. Foregrounding feminine emotions and feelings is also a feature in $D a$. The narrator's emotions in times of her father's death (pp. 168-222), her feelings upon seeing the injured and the dead in hospital and in the front throughout the narrative, and her emotions on her brother's death (pp. 293-339) are just a few illustrations of women's feelings and emotions that are hardly present in men's writing. $D a$ (2014) includes a series of scenes that are recounted to improve the status of women. Zahra's effort to break the patriarchal and traditional taboo that women should not reveal personal information and family background can be seen on several occasions throughout the memoir. Zahra Hosseini is constantly questioning the patrilineal culture of the society through doing tasks that are usually men's jobs and stands firm against anyone warning her that women cannot or should not do the task. For instance, when she wants to dig graves, a man gravedigger tells her: "This is not a playing. You can't dig graves," (p. 99) she gets mad and responds "Why not? Is that what you men think? We're weak just because we're women" (p. 99). Another similar instance is when a man tells her that she cannot lift the stones because they are too heavy but she says very defiantly "Yes I can" (p.137). When Zahra decides to inform the authorities of what is going on and ask for more people to come and wash the copses, Zeinab asks her "Who is going to listen to you?...This is something a man should do, go there and demand new people" (p. 103), and Zahra responds "What's wrong with us? We have tongues, don't we?" (p. 103). On many occasions, Zahra defies top military male officers asking her and her friends to leave the front because it is dangerous; she oftentimes responds "If it's dangerous, what keeps you here? I'm no different from you" (p. 206), "Don't think that only men can fight; women can also' (207) and 'We won't go back...We're here and we know what we are doing" (p. 457). This is Zahra's way to protest against the presumption that women are weak and submissive. These excerpts and many other examples such as taking care of the cemetery at nights (p. 149), accepting responsibility to take care of the family (p. 133), calming down the uncontrollable crowds at times of invasion (p. 197), and cleaning and repairing guns and reloading magazines (pp. 365-6) suggest that Zahra is reinstating her own agency and women's in general. Her tough, tenacious, brave and ready-to-help-at-any-time personalities challenge the stereotypical role of Iranian women. $D a$ has been received well in the country and has seen 158 reprints as of late 2019 according to the publisher. Thus far, it has been the focus of 11 theses, 220 news pieces, 150 interviews, and 70 sessions of review. Iranian Scholars such a Javadi Yeganeh and Sohofi examined the reasons for the popularity of the memoir. Similarly, Laetitia Nanquette, in her paper 'An Iranian Woman's Memoir on the Iran-Iraq War: The Production and Reception of $\mathrm{Da}$,' studied the production, distribution and reception of this memoir of 'Sacred Defense.' In a paper entitled 'Ecriture Feminine: Feminism and Nationalism in Seyyedeh Zahra Hosseini's 'One Woman's War: Da,' Zeiny (2019) has explored how Da constructs a feminine writing that challenges patrilineal culture and highlights women's roles in nation-building projects like the Iran-Iraq war. $D a$ has received several awards including the 
2009 Jalal Al-e Ahmad Award, the 2009 Book of the Year Award, and the 2009 Shahid Qanipour Prize. The memoir was translated to English by Paul Sprachman and published by Mazda Publishers in 2014.

I'm Alive (2012) is yet another life narrative written by Masoumeh Abad about the IranIraq war (1980-1988) and her captivity in Iraq's prisons for four years. It consists of eight chapters. The first and second chapters portray Masoumeh's childhood and adult life in Abadan. Chapter three depicts the Islamic Revolution of 1979. Chapters four, five, six and seven are detailed accounts of her captivity in Iraq's prisons. The last chapter accommodates pictures and documents of war and her captivity to prove the accuracy of what has been written. This book takes the genre of alternative narratives up a notch and depicts an unseen and unheard account of women's captivity in Iraq's prisons. There are many occasions that put diasporic narratives' accounts of Iranian women's submissiveness to shame. For instance, when the Iraqi soldiers took her and a group of Iranian men, they insisted on cuffing her hands, not the men soldiers, because they thought that "Iranian women are more dangerous than Iranian men" (p. 159). In another episode, the warden of the prison asks an Iranian male prisoner of war "why is it that these women pester, trouble and ridicule our guards? Aren't they afraid of anything? Do all Iranian women share this bravery?" (p. 281). Iranian women's fortitude and strength have also been admitted by Iranian men in statements such as "a woman shakes the cradle with one hand and shakes the world with the other hand" (p. 271) and "I'm sure Masoumeh is patient and no one can break her tenacity" (386). Aside from defying the orientalist stereotypes of the Iranian Muslim women as passive and victim in need of saving, Masoumeh questions the traditional taboo that women should not reveal personal information and their own women's needs. Although with reservation, she writes how "the unhygienic conditions of the prison delayed their periods by several weeks" (p. 265) and related their request to receive sanitary pads (p. 265). Another characteristic that makes this book as an alternative narrative is the attention to Iranian literature. Persian poetry, particularly Rumi's poetry, is scattered throughout the book (pp. 100,132,277,362,368). Masoumeh also alludes to Russian literature and speaks of Leo Tolstoy (p. 433). I'm Alive (2012) has received the 16th Sacred Defense Book of the Year award and has seen 212 reprints as of March 2019. Having become the biggest bestseller in the shortest period, I'm Alive has outsold and gone through more reprints than any other life narratives in the genre of 'Sacred Defense.' The most common concern that recurs frequently in these life narratives is the desire to rectify misperceptions and assumptions, and break the stereotypes that surround Iran and Iranian women. This sort of alternative narrative resonates well with Terdiman's definition of counter-discourse in relation to a dominant discourse by referring to it as a passion to 'displace and annihilate a dominant depiction of the world' (1985, p. 12). These alternative narratives produced by the 'insider within' collectively negate the diasporic depiction of Iran and Iranian women.

\section{CONCLUSION}

Marivan Lake at Six O'clock, Eternal Fragrance, Da, and I'm Alive are just a few examples of alternative life narratives produced by the 'insider within.' They are all within the genre of 'Sacred Defense' literature which is usually state-sponsored. However, the fact that these life narratives are state-sponsored does not diminish their value as alternative narratives. Although one expects to see women as a faithful and attentive housewife or mother of a martyr in statesponsored 'Sacred Defense' literature, these narratives demonstrate strong-willed and independent young women who are bold enough to participate in the war and have the audacity to interrogate the patrilineal cultural patterns of the society. These alternative narratives are strikingly beautiful ventures of Iranian women's self-definition and self-valuation that travel beyond the conventional. All of these alternative narratives turn the diasporic narratives' 
culturally defined, silent and passive Iranian woman into a self-defined and articulate woman. While the diasporic narratives continually represent Iranian women as passive, victims and voiceless and blame the Islamic Republic and its imposed restrictions on women, the alternative narratives question the imposed cultural restrictions and bring up potent female characters to counter the orientalist stereotypes of female passivity. Alternative narratives produced by the 'insider within' delegitimise many dominant perceptions about Iran and Iranian women that have served towards dehumanising and rendering invisible the Iranian other. Thus, these alternative narratives have the power to threaten the Orientalist stereotypical representations maintained and controlled by the conditioned way of seeing; and they have the potential to produce a new way of seeing. This positive shift in vision generates a positive perspective towards Iran and Iranian women. What is striking about these alternative narratives is that, unlike those diasporic narratives that perpetrate and perpetuate the orientalist stereotypes, the contemporary Iranians can relate well with these narratives. These alternative narratives, ipso facto, can serve as a better model to understand Iran and Iranian women.

\section{REFERENCES}

Abad, Masoumeh. (2012). I am Alive. Tehran: Borooj Publications.

Banks, J. A. (1998). The Lives and Values of Researchers: Implications for Educating Citizens in a Multicultural Society. Social Problems. 27(2), 209-219. https://doi.org/10.3102/0013189X027007004

Chavez, Christina. (2008). Conceptualizing from the Inside: Advantages, Complications, and Demands on Insider Positionality. The Qualitative Report. 13(3), 474-494.

Fotouhi, Sanaz. (2015). The Literature of Iranian Diaspora: Meaning and Identity since the Islamic Revolution. London, New York: I.B.Tauris. https://doi.org/10.5040/9780755608539

Hosseini, Seyyedeh Azam. (2014). One Woman's War: Da (Mother): The Memoirs of Syeddeh Zahra Hosseini. (Paul Sprachman, Trans.). Costa Mesa: Mazda Publishers. (Original work published 2008).

Javadi Yeganeh, Mohammad Reza and Sohfi, Seyed Mohammad Ali. (2013). Revayate Zanane az Jang: Tahlile Enteghadi-e Ketabe Khaterate $D a$ ( Women's Narrative of War: Critical Analysis of Da). Naghde Adabi. 6, 85-110.

Mandel, Barrett. J. (1980). Full of Life Now. In James Olney (Ed). Autobiography: Essays Theoretical and Critical, 49-72. Princeton, NJ: Princeton University Press. https://doi.org/10.1515/9781400856312.49

Nafisi, Azar. (2003). Reading Lolita in Tehran. New York: Random House.

Nanquette, Laetitia. (2013). An Iranian Woman's Memoir on the Iran-Iraq War: The Production and Reception of Da. Iranian Studies. 46(6), 943-957. https://doi.org/10.1080/00210862.2013.810077

Nash, Geoffrey. (2012). Writing Muslim Identity. London: Bloomsbury Publishing.

Nowbakht, Parvin. (1981). Sa'at-e Shesh, Daryache-ye Marivan [Marivan Lake at Six O’clock].Tehran: Sepehr.

Ramhormozi, Masoumeh. (2003). Eternal Fragrance. Tehran: Sureye Mehr Publication.

Satrapi, Marjane. (2003). Persepolis: The Story of a Childhood. New York: Pantheon Books.

Taj-ol Saltaneh. (1982). Khaterat-e Taj-ol Saltaneh [Taj-ol Saltaneh's Memoirs]. Mansureh Ettehadiyeh and Sirus Sa'dvandiyan (Eds). Tehran: Nashr-e Tarikh-e Iran.

Terdiman, Richard. (1985). Discourse/Counter-Discourse: The Theory and Practice of Symbolic Resistance in Nineteenth-Century France. New York: Cornell University Press. 
Trinh T Minh-ha. (1991). When the Moon Waxes Red: Representation, Gender and Cultural Politics. New Yourk: Routledge.

Trouillot, Michel- Rolph. (1995). Silencing the Past. Boston: Beacon Press.

Whitlock, Gillian. (2007). Soft Weapons: Autobiography in Transit. Chicago: University of Chicago Press. https://doi.org/10.7208/chicago/9780226895277.001.0001

Zeiny, Esmaeil \& Noraini Md. Yusof (2016). The Said and Not-said: New Grammar of Visual Imperialism. GEMA Online ${ }^{\circledR}$ Journal of Language Studies. 16(1), 125-141.

Zeiny, Esmaeil. (2019). Ecriture Feminine: Feminism and Nationalism in Seyyedeh Zahra Hosseini's 'One Woman's War: Da.' 3L: Language, Linguistics, Literature. 25(3), 115125. https://doi.org/10.17576/3L-2019-2503-09

\section{ABOUT THE AUTHORS}

Esmaeil Zeiny is a Researcher the Department of English Language and Literature, Golestan University. His research interests focus on the intersection of Literary Studies, Cultural Studies, Visual Culture and Political Theory. His work addresses questions of identity, representation, colonialism and postcolonialism.

Noraini Md. Yusof is an Associate Professor at the Institute of Malaysian and International Studies, Universiti Kebangsaan Malaysia. Her areas of specialization include Literature in English, Revisionism and Literature, Creative Writing and Visual Culture.

Abdolbaghi Rezaei Talarposhti is an Assistant Professor at the Department of English Language and Literature, Golestan University. His research interests include English Literature, Literary Criticism and Islamic Texts. 